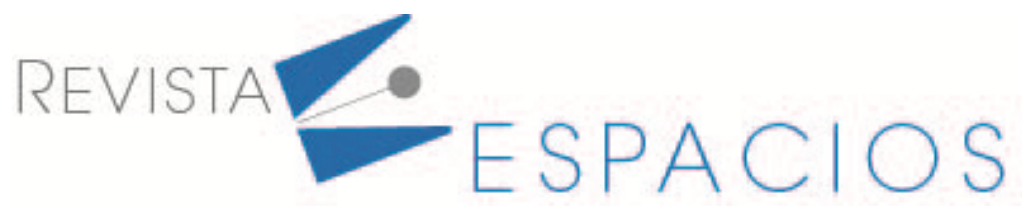

\title{
Emotional regulation and perceived stress levels during physical-preventive distancing due to the SARS COVID-19 pandemic in students of the Universidad Distrital Francisco José de Caldas Bosa facilities (Colombia) - 2020
}

\author{
Regulación emocional y niveles de estrés percibidos durante el distanciamiento físico \\ preventivo por la pandemia SARS COVID-19 en las mujeres estudiantes de la Universidad \\ Distrital Francisco José de Caldas Sede Bosa-2020
}

\author{
BELTRÁN,Nubia Y. ${ }^{1}$ \\ MARTINEZ, Anderson ${ }^{2}$ \\ RODRÍGUEZ, Juan D. ${ }^{3}$ \\ VALDERRAMA, Yessica M. ${ }^{4}$
}

\begin{abstract}
The study corresponds to the analysis of 126 female university students at the Bosa facilities of the Universidad Distrital Francisco José de Caldas in Bogotá, aged between 17 and 33 years. The perceived stress scale (EEP-14) was used; To evaluate emotional regulation, the emotional regulation questionnaire (ERQ) was used where it was evaluated $(C R=44 \%$ ) (cognitive reevaluation) and $(S E=37 \%$ ) (emotional suppression); the results showed that on average perceived stress is moderate (40.2\%). key words: Emotional Regulation, Covid-19, Perceived Stress, Women University Students.

Resumen

El estudio corresponde al análisis de 126 mujeres estudiantes universitarias de la sede de Bosa de la Universidad Distrital Francisco José de Caldas de Bogotá, con edades comprendidas entre los 17 y los 33 años. se usó la escala de estrés percibido (EEP-14); para evaluar la regulación emocional, se usó el cuestionario de regulación emocional (ERQ) donde se evaluó ( $\mathrm{RC}=44 \%)$ (reevaluación cognitiva) y $(\mathrm{SE}=37 \%)$ (supresión emocional); los resultados demostraron que en promedio el estrés percibido es moderado (40.2\%).
\end{abstract}

Palabras clave: Regulación Emocional, Covid-19, Estrés Percibido, Mujeres Estudiantes Universitarias.

\footnotetext{
${ }^{1}$ Docente Investigadora. Programa Profesional en Administración Deportiva. Universidad Distrital Francisco José de Caldas, Colombia Email: nybeltranp@udistrital.edu.co

${ }^{2}$ Estudiante Investigador. Programa Profesional en Administración Deportiva. Universidad Distrital Francisco José de Caldas, Colombia Email: andmartinezm@correo.udistrital.edu.co

${ }^{3}$ Estudiante Investigador. Programa Profesional en Administración Deportiva. Universidad Distrital Francisco José de Caldas, Colombia Email: juandrodriguezr@correo.udistrital.edu.co

${ }^{4}$ Estudiante Investigadora. Programa Profesional en Administración Deportiva. Universidad Distrital Francisco José de Caldas, Colombia Email: ymvalderramal@correo.udistrital.edu.co
} 


\section{Introduction}

This research was built from the concerns, dissertations and disquisitions that were had about the documentary review of mental health in a Colombian and global context in front of the intervention models from institutional well-being in the institutions of higher education of Bogotá, likewise The female population was the focal research interest for the differential gender dynamics that must be taken into account in the research exercises.

This led to the construction of an analysis path using the adjusted emotional regulation questionnaire (ERQ) Gross \& John (2003) of the female students of the UDFJC, (Bosa headquarters), during the period of preventive physical distancing due to the SARS COVID-19 pandemic.

\subsection{Women and Sars Covid-19}

The pandemic has brought deadly repercussions and effects on physical and mental health in thousands of people around the world, however,

"Disease outbreaks affect women and men differently, and pandemics exacerbate existing inequalities between women and girls (...) It is important to take this into account by considering the differential impacts associated with detection and access to treatment for women and men. "ONU (2020).

Consequently with the aforementioned, the preventive physical distancing time, lived in the homes can generate emotional disorders in the population, especially in women such as: depression, anxiety, anger, stress, gender violence, intimidation and intra-family aggression, thus according to the ONU (2020). this facilitates the appearance of mental and behavioral disorders.

The UN regional office for the Americas and the Caribbean, in its gender and covid-19 report, alluded to the fact that there will be no effective response to the pandemic if the impacts on women are not addressed and the dynamics of Gender in the response, as a recommendation of the organization, member countries were entrusted with allocating sufficient resources to respond to the needs of women and girls, avoid reducing funds for existing health programs, and ensure the availability of data disaggregated by sex and gender analysis giving priority to essential multisectoral basic services, including social, food and health services, this means that health care models for women must be comprehensive during the pandemic and not only in a welfare. ONU (2020).

\subsection{Women and Stress}

According to (Caldera et al., 2007) one in four people in the world suffers from a chronic stress problem and in large cities it is estimated that 50 percent of the inhabitants have a mental health problem related to this. In the case of university students (Mazo et al., 2013) they mention that the majority suffer from academic stress since the demands of the university environment cause a negative alteration in them.

Women pay more attention to emotions and are more empathetic, and this is associated with a ruminative coping style focused on their own emotions, while men have higher levels of emotional self-regulation in stressful situations (Martínez et al., 2015).

\subsection{Women and Emotional Regulation}

The achievement of regulation and emotional management is one of the multiple concerns currently facing nations and public health organizations around the world; In countries like Colombia, it can be seen that statistics have increased with respect to pathologies derived from an inadequate management of emotional regulation; when the humans beings do not manage their emotions, they are dominated by stress, anxiety, lack of appetite, depression and in the worst cases lead to behaviors that can end in the act of suicide. (Muñoz-Martínez et al., 
2016). In Colombia, the scientific literature related to Self-regulation and management of emotions in university settings is barely incipient, added to its application in the female population.

\section{Methodology}

Research with a mixed approach, addresses qualitative and quantitative elements, the design of the research is descriptive, non-experimental. A Google Forms questionnaire was applied to those who voluntarily participated in the research. 126 active female university students from the Bosa facilities of different university careers (sports management, Archives, social communication, technology in environmental sanitation, sanitary engineering, environmental administration, etc. among others) of the Universidad Distrital Francisco José de Caldas. The entire protocol of the bioethics committee of the University provided for this purpose was followed, keeping the anonymity of the participants, respecting international ethical standards.

\subsection{Research Instruments}

\subsubsection{EPP-14}

The EEP-14 perceived stress scale was adapted in relation to the circumstances subject to the measure of mandatory physical-preventive distancing by SARS-Cov2. The scale consists of 14 items with polytomous response patterns that are grouped on a Likert scale that scores from 1 to 5: i) never; ii) almost never; iii) sometimes; iv) almost always and v) always. Items 4, 5, 6, 7, 9, 10 and 13 have an inverse scoring model.

Thus, the scores are between 0 and 70; high scores indicate higher levels of perceived stress. These levels were subjected to the visual grouping method, obtaining five ranges that facilitate the analysis: scores from 0 to 14 indicated a low level of perceived stress; from 16 to 28 a mild level is represented; 29 to 42 is related to a moderate level, while 43 to 56 corresponds to an intense level and from 57 to 70 a severe stress level.

\subsubsection{ERQ- Adapted}

The Emotional Regulation Questionnaire (ERQ) by Gross \& John (2003) was applied, this is widely used in the evaluation of individual differences in emotional regulation and suppression, the items specifically evaluate how emotions are managed and regulated, It is made up of 10 statements, with a Likert-type scale scoring between 1 and 7 , which allows achieving a minimum mean score of 1 and a maximum of 7.

This questionnaire assesses two emotional regulation strategies, it initially focuses on the emotional experience itself and on the other hand, emotional expression, that is, how emotions are evidenced in attitudes, behaviors and / or through verbal and non-verbal communication. Cognitive reevaluation is a form of cognitive change that involves the elaboration of a new emotional experience that potentially has minimal emotional impact (When you want to feel more pleasant emotions, you change the way you think about the situation) (six items) and the suppression emotional (four items).

High scores on the Cognitive Reassessment show a significant presence of it, as does the emotional suppression. This refers to the way of agreeing on the emotional response that circumscribes the inhibition of expression (when experiencing pleasant emotions, special care is taken not to express or externalize them)

According to (Pineda et al., 2018), the Spanish version of the ERQ is a valid and reliable instrument, appropriate levels of internal consistency, reliability and convergent and discriminant validity to assess emotional regulation in Spanish-speaking population. The use of reassessment is associated positively with positive emotions and negatively with negative emotions, whereas suppression is associated with an opposite pattern. 


\subsection{Population}

The population is 126 female university students active in the 2020-I university period belonging to the Bosa Porvenir facilities at the Universidad Distrital of Bogotá. Convenience sampling was preferred. An online questionnaire-type instrument (Google Forms) was provided in which the participant performed expressly, unequivocally and voluntarily by self-completion, obeying the guidelines of the University Bioethics Committee.

\section{Results}

\subsection{Perceived Stress Levels}

Regarding this variable, the students show a (13.5\%) corresponding to a level of perceived stress that is mild, $(46.0 \%)$ moderate, $(34.9 \%)$ intense and (5.6\%) severe (Table 1).

Table 2

Perceived Stress Levels

\begin{tabular}{|c|c|c|c|c|c|}
\hline \multicolumn{2}{|c|}{} & Frequency & Percentage & P. valid & P. accumulated \\
\hline \multirow{4}{*}{ Valid } & mild & 17 & 13,5 & 13,5 & 13,5 \\
\cline { 2 - 6 } & Moderate & 58 & 46,0 & 46,0 & 59,5 \\
\cline { 2 - 6 } & Intense & 44 & 34,9 & 34,9 & 94,4 \\
\cline { 2 - 6 } & Severe & 7 & 5,6 & 5,6 & 100,0 \\
\cline { 2 - 6 } & Total & 126 & 100,0 & 100,0 & \\
\hline
\end{tabular}

Source: self made

\subsection{Emotional Regulation Distribution}

In terms of emotional suppression (Figure 1 Emotional Regulation Distribution), the students reported $37 \%$ high, $24 \%$ mild, $20 \%$ Standard, $17 \%$ maximum and $2 \%$ minimum.

In terms of cognitive reassessment (Figure 1 Emotional Regulation Distribution), the students reported $44 \%$ high, $29 \%$ standard, $21 \%$ maximum, and $6 \%$ mild.

Figure 1

Emotional Regulation Distribution

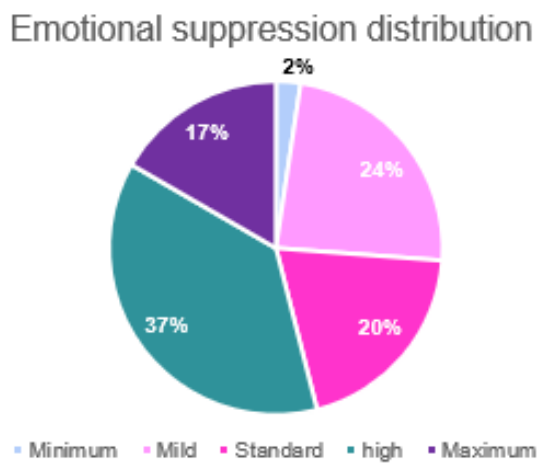

Cognitive reevaluation distribution

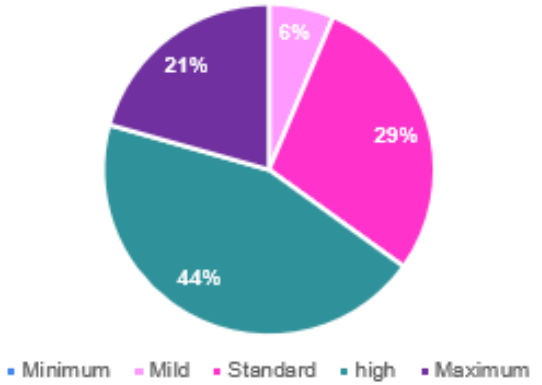

Source: self made.

\subsection{Age}

In total, 126 active female university students from the Francisco José de Caldas District University participated in academic programs at the Bosa campus. The application of the instrument was executed from April 1 to May 31 , 2020. In relation to age (Figure 2$)$, the average students are (ME $=21.341$ ) years, $2.38 \%$ of the sample $(n=3)$ is in a range less than or equal to $\leq 17$ years, $27.78 \%(n=35)$ were between 17 and 19 years old, $42.06 \%(n=53)$ 
between 20 and 22 years old, 18.25\% $(n=23)$ between 23 and 25 years, $7.14 \%(n=9)$ between 26 and 28 years and $2.38 \%(n=3)$ over 28 years. The longest-serving student reported 32 years.

Figure 2

Age Range

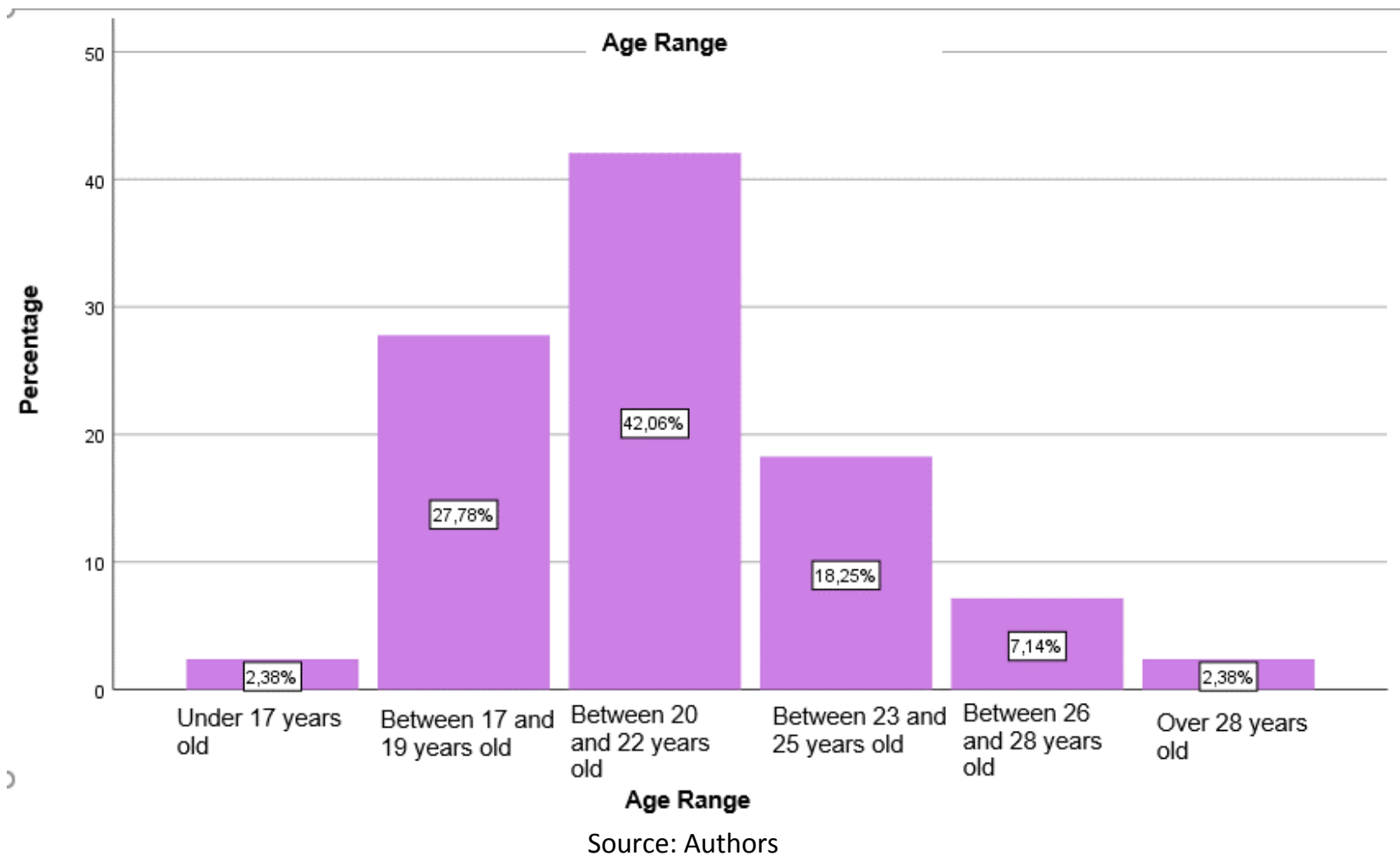

\subsubsection{Age and Perceived stress}

Regarding the behavior of the stress and age variables (Figure 3), the data denote a higher concentration of subjects in the age range between 20 and 22 years, this coincides with the moderate stress level ( 25 students). Likewise, the age range $\leq 17$ years corresponds to the level of mild stress. Regarding age $>28$, only one subject reported severe stress.

Figure 3

Levels of perceived stress for age

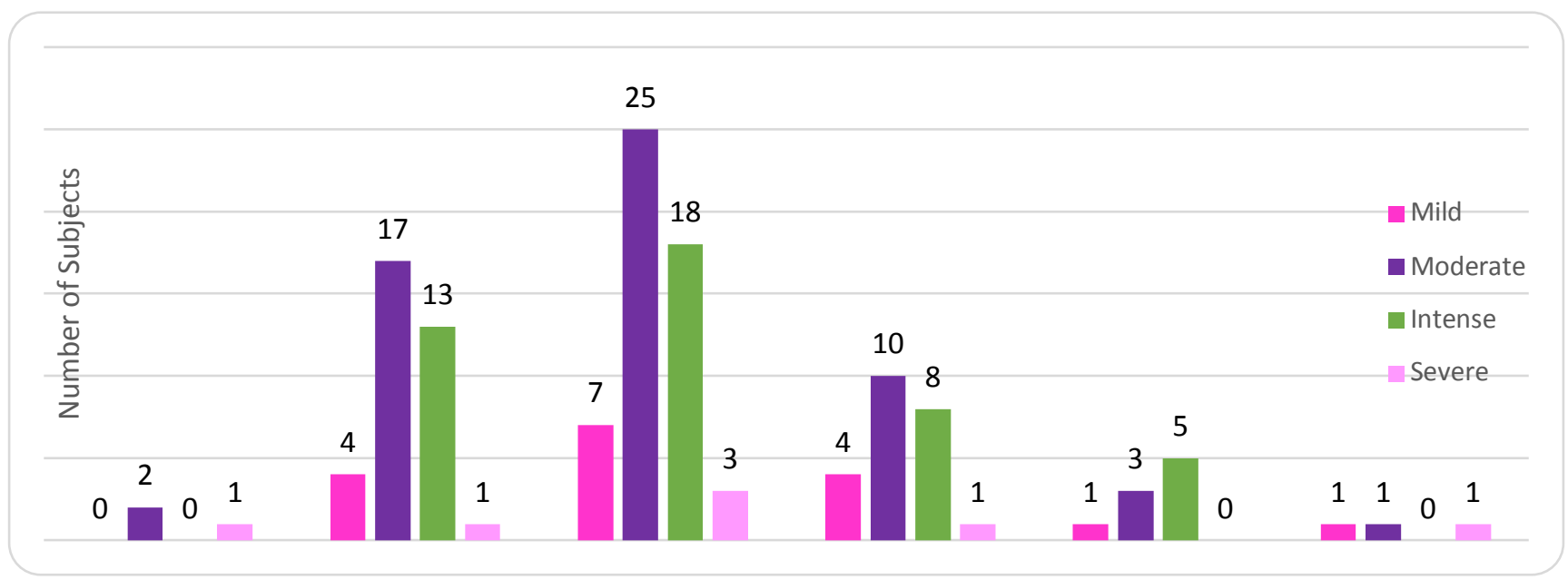

Source: Authors 


\subsubsection{Age and emotional suppression}

Regarding the behavior of the variables, it can be seen that the highest emotional suppression is located in the age range between 20-22 years (Figure 4); likewise, the age range between 23-25 years shows the most homogeneous behavior with regard to emotional suppression. Only 3 subjects of the 126 total show minimal emotional suppression.

Figure 4

Emotional suppression and age

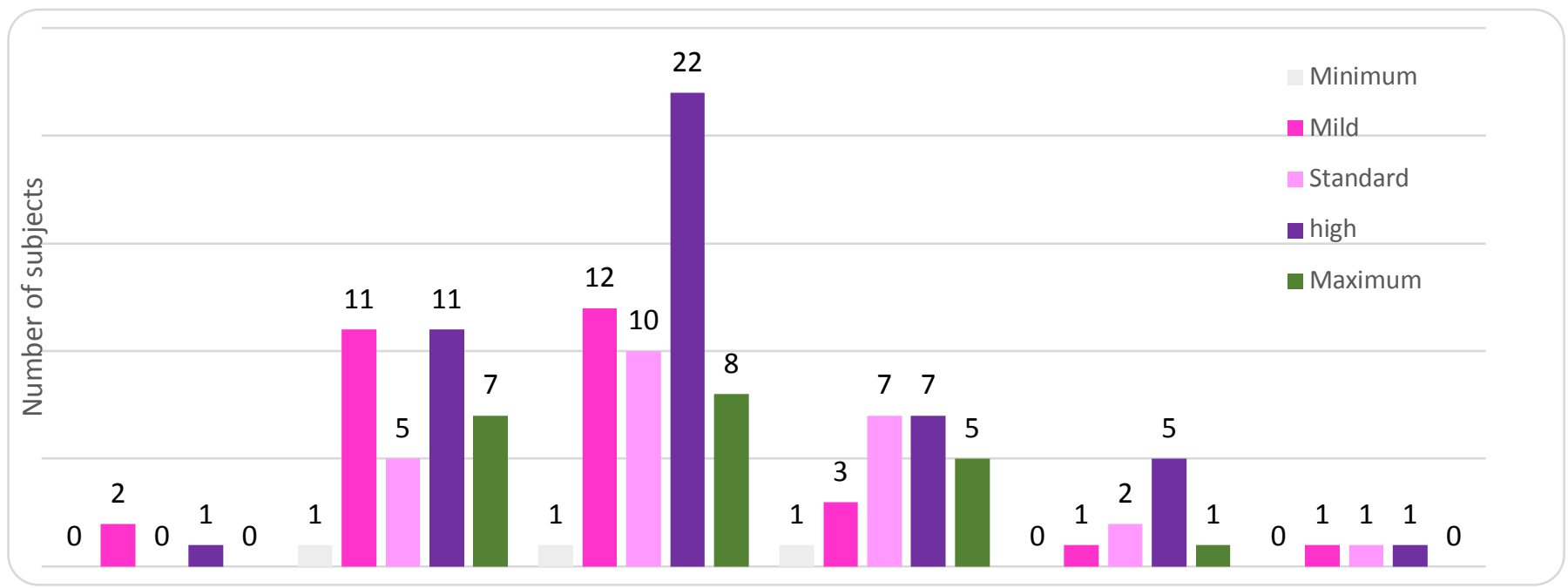

Source: Authors

\subsubsection{Age and Cognitive Reevaluation}

In regarding the behavior of the variables, it can be seen that the high cognitive reappraisal is located in the age range between $20-22$ years (Figure 5); likewise, the age range $>28$ years shows the most heterogeneous behavior with regard to cognitive reappraisal.

Figure 5

Age and Cognitive Revaluation

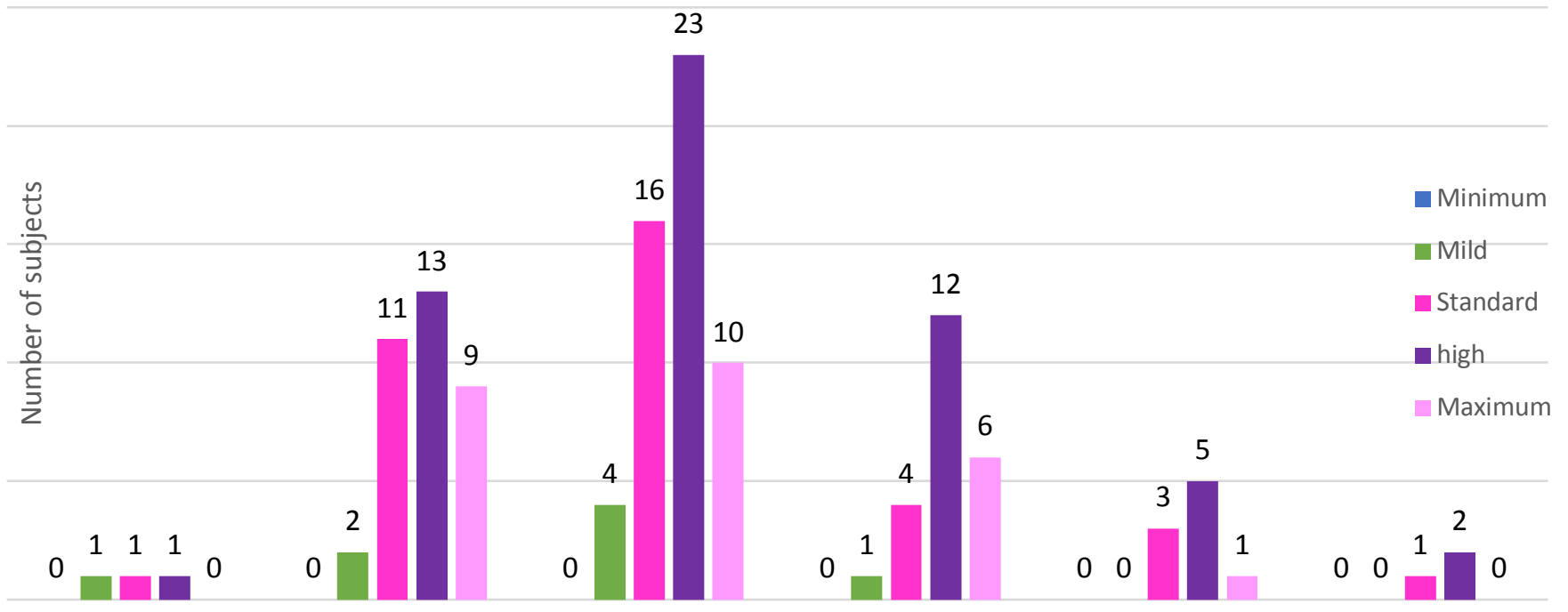

Source: Authors 


\subsubsection{University career and perceived stress}

Figure 6

University career and perceived stress

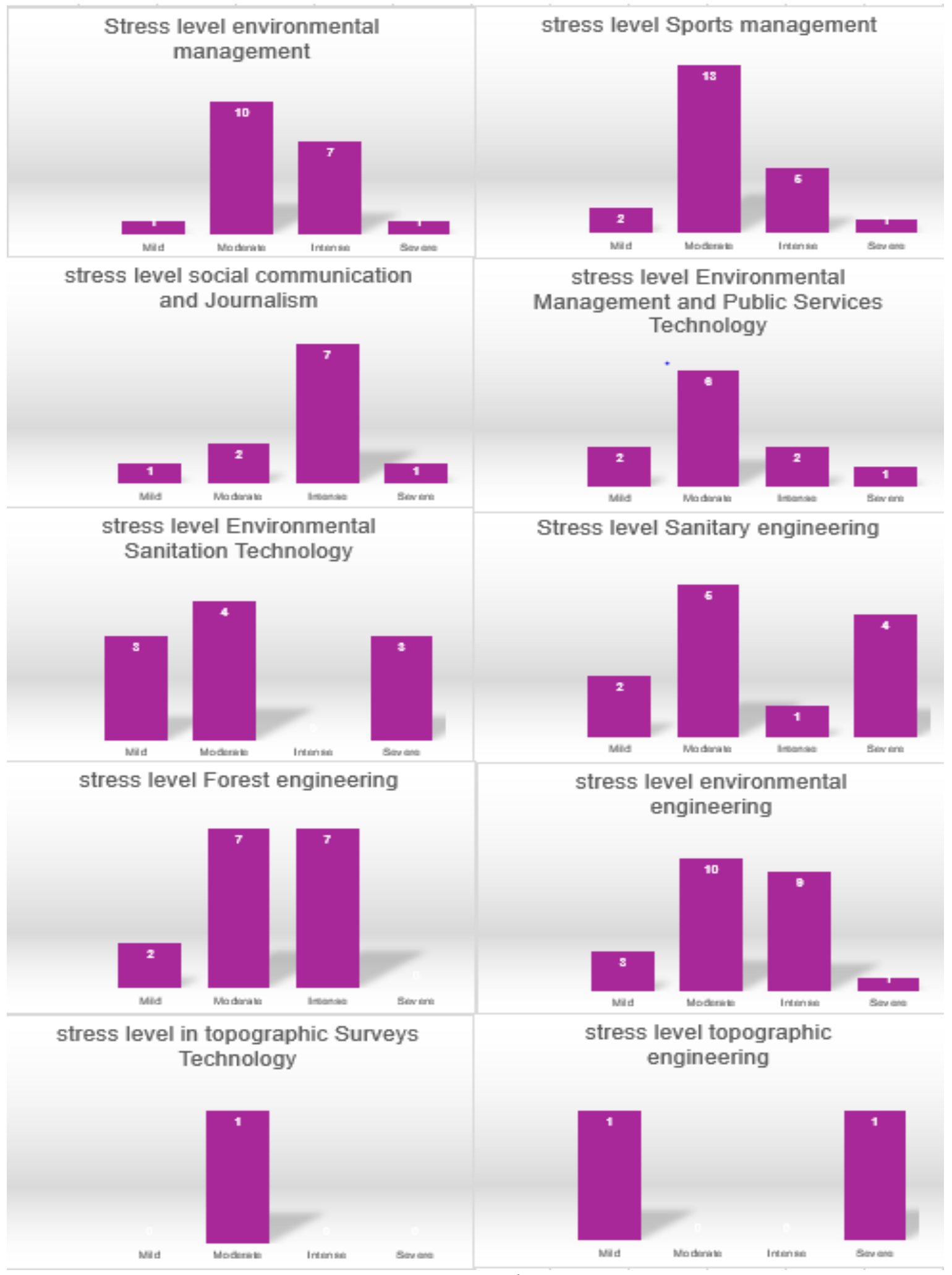

Source: Authors 
For the data analysis, the students who corresponded to different university careers of the Faculties of Environment and Natural Resources and Education Sciences were taken into account (Figure 6); in such a way that (18.25\%) belonged to Environmental Engineering, (16.67\%) Sports management , (15.08\%) Environmental management , (12.70\%) Forest Engineering, (9.52\%) Sanitary Engineering, (8.73\%) Social Communication and Journalism \& Technology in Environmental Management and Public Services, (7.94\%) Technology in Environmental Sanitation, (1.59\%) Topographic Engineering, (0.79\%) Technology in Topographic Surveys.

In the case of Social Communication, Environmental management and Forest Engineering show a homogeneous level of intense stress, while Sports Administration, Tech. Environmental Management and public services, topographic engineering and Environmental Engineering show a uniform severe stress level.

\subsection{Socioeconomic status}

Status 1 presents intense stress levels (70\%), evidencing that it is the most prone to severe and intense stress (Figure 7); on the other hand, status 2 shows moderate stress levels (46.03\%), status 3 presents all stress levels, with moderate prevailing. Despite this, the largest number of people who consider the cognitive reevaluation of emotions irrelevant.

Regarding status 4, the behavior of the data is homogeneous in terms of perceived stress and emotional suppression, therefore they are not very prone to repressing emotions, but on the contrary to expressing them.

Figure 7

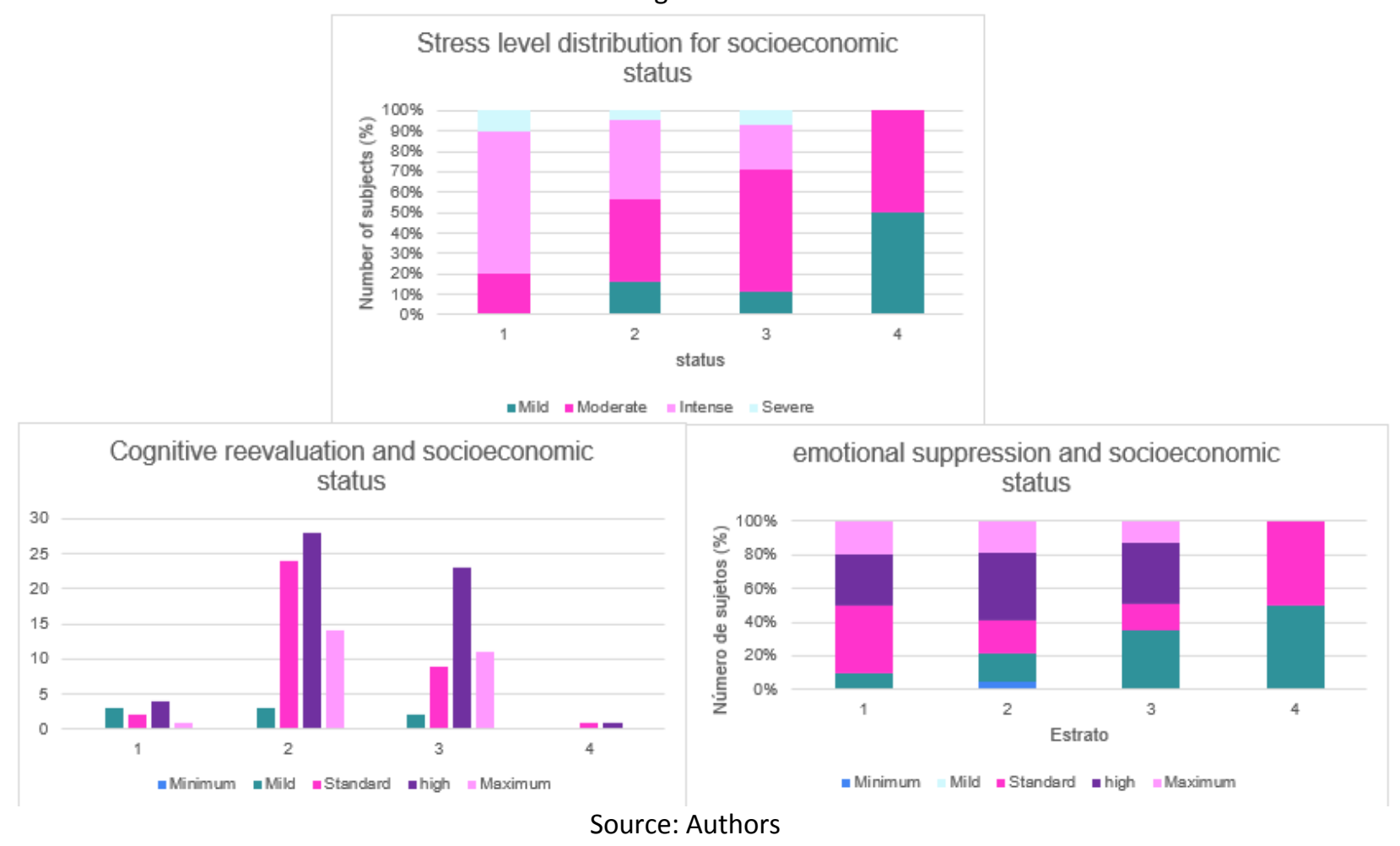

\subsection{Semester}

In terms of perceived stress, the semesters where students present intense stress are 2 nd, 3 rd and $9^{\text {th }}$ (Figure 8). Likewise, moderate stress prevails in the 4th and 8th semesters. The Results show that the semesters where cognitive reevaluation predominates is in the 7th semester, and on the contrary, emotional suppression in the 4th. 
Results show that the semesters where cognitive reassessment predominates is in the 7th semester, and on the contrary, emotional suppression in 4 th.

Figure 8
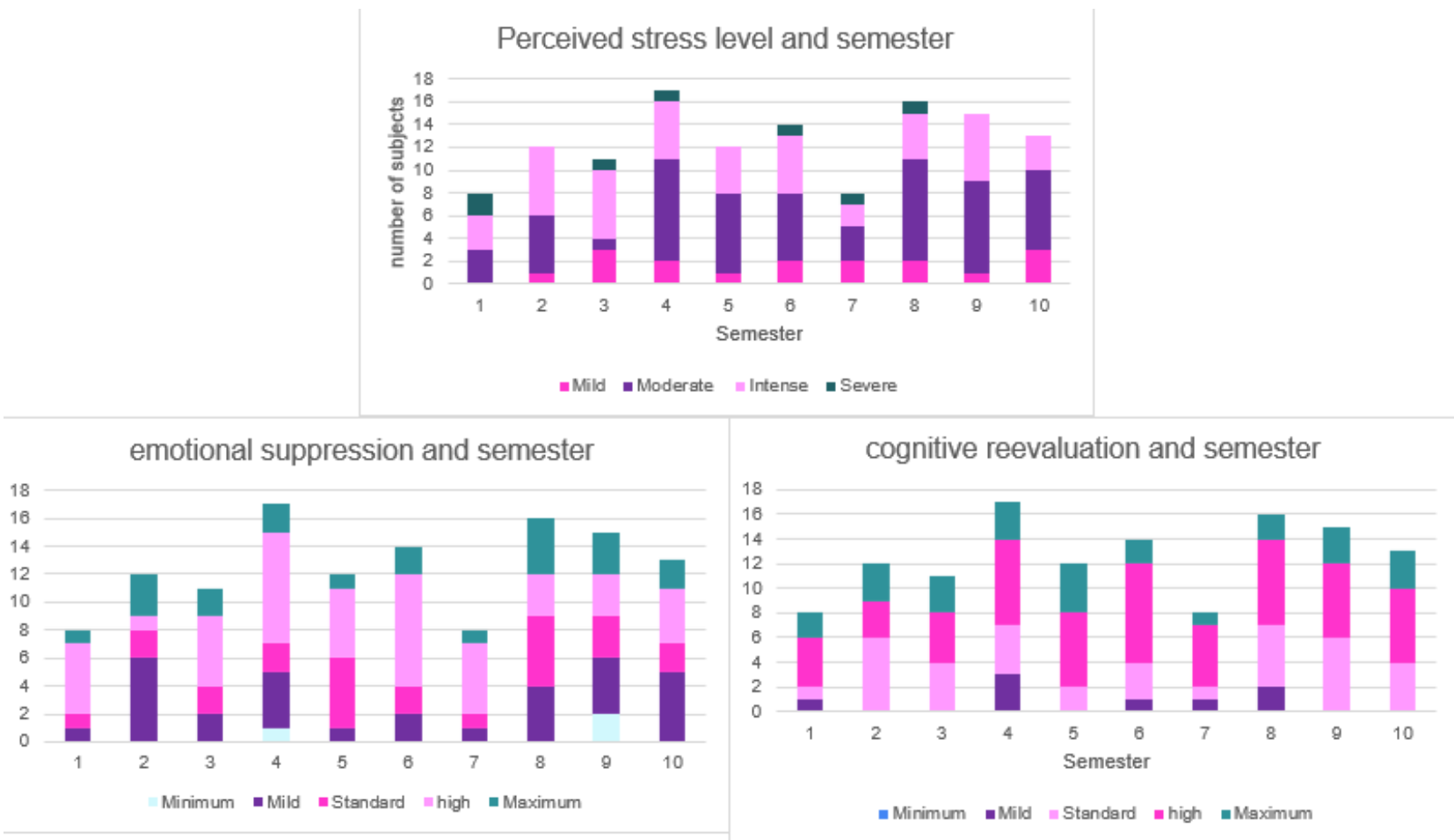

\subsection{Quarantine days}

Regarding the level of stress per days of quarantine (Figure 9), the students with the highest moderate stress (31.74\%) were in physical-preventive distancing around 0-20 days, consequently (26.19\%) presented intense stress in the same range of days.

The students who remained between 0-20 days in physical-preventive distancing at the beginning of the quarantine present high cognitive reappraisal, therefore, they present a lower risk of suppressing their emotions, on the contrary, the more days elapsed the emotional suppression tends to rise. 
Figure 9

Quarantine days

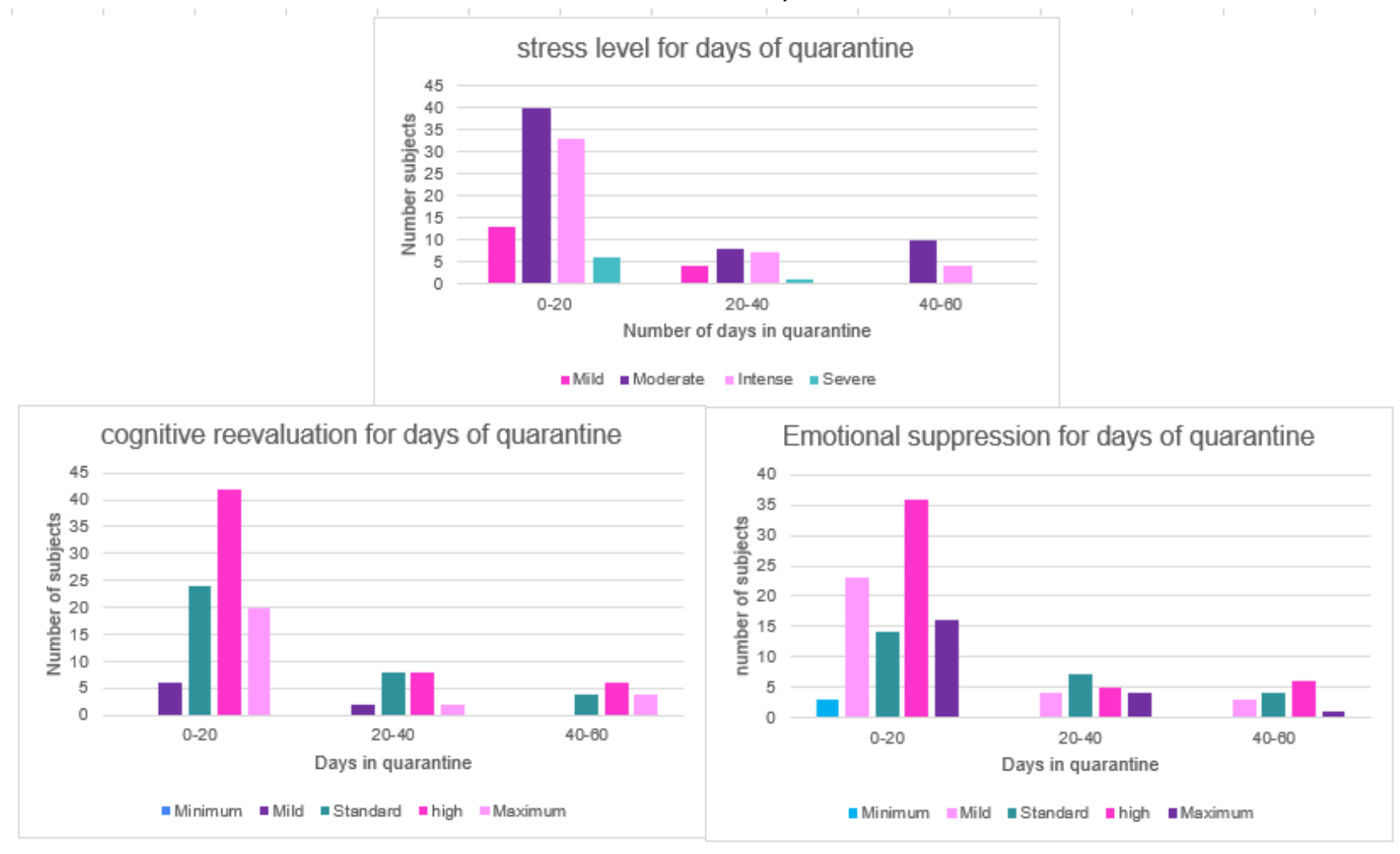

Source: self made.

\section{Conclusiones}

Taking into account that self-regulation is a cognitive exercise of control, as (Gross, 1998; Richards \& Gross, 2000) cited by (Gargurevich, 2008) indicated two mechanisms are required to regulate emotion: cognitive reappraisal and suppression emotional. These two are clearly differentiated, re-evaluation deals with transforming the emotional experience at the moment of its configuration or origin, managing to modify it, while suppression only modifies the emotional expression, trying to hide or repress the experience without managing to change it at all. . Thus, cognitive reassessment is the strongest and healthiest means for accurate emotional regulation.

In this vein with regard to age, an exploration carried out (Wang and Saudino 2011) stress, and these skills may differ over time. of age "(p. 98). In agreement, this research found that no age group behaved the same regarding this variable, however all age ranges showed that high cognitive reappraisal prevails, additionally, students between 17 and 19 years of age report the lowest number of subjects in that group, with high cognitive reappraisal, when compared with the age range between 20 and 22 years old, who show the highest concentration of population with high reappraisal, while the age range $>28$ years shows the most heterogeneous behavior with regard to the variable in question, this indicates not only that the cognitive reappraisal is modifiable with age but that the existence of factors over the course of 20 years that causes it to increase can be suggested.

Taking into account that in Colombia the scientific literature concerning the regulation and management of emotions in university settings is in progress, especially with regard to the female population, the National University of Colombia carried out a research study where it was evidenced that, in the university population, is 
emphasized as risk factors: lasting more than eight hours a day alone, belonging to the female gender, and being a victim of violence. (Calvo G. et al., 2003).

Stress and multiple mental pathologies are circumstances that can be intervened by being established in stages of etiology, they are also noticed, thus achieving a significant improvement in emotional and social well-being through emotional regulation.

In this order of ideas, as they refer (Brooks et al 2020), the generality of the studies examined warn of harmful psychological consequences from restriction and free mobility and circulation, massive preventive physical distancing in homes due to the 2019 coronavirus outbreak (COVID-19), include symptoms such as post-traumatic stress, uncertainty, mistrust, bewilderment, and anger. The stressors circumscribe a longer stay in quarantine, fear of contagion, fear of death, frustration, anguish due to job and financial losses of one's own or those of close family members.

Now, starting from the concept of perceived stress which comes from the transactional theory of stress, which conceptualizes it as a specific relationship between the individual and her environment, when the latter is evaluated by the subject as threatening or potentially dangerous for well-being (Lazarus \& Folkman, 1984).

Perceived stress can be seen in people who are usually under constant pressure, for example, students at any university in the world.

There is enough evidence to conclude that there is a psychological impact and there are effects on the mental health of university students from the careers of Sports Administration, since $16.67 \%$ reveal a severe stress level, as in Technology in Environmental Management and Public Services, Topographic Engineering and Environmental Engineering, from the Bosa headquarters of the Universidad Distrital Francisco José de Caldas in Bogotá.

While the students of the Social Communication career (8.73\%) exhibit a level of intense perceived stress, as well as those who belong to Environmental Administration (12.70\%) and Forest Engineering (in 9, 52\%).

It is important to consider these results, which reveal the vulnerability of the university academic community, in the face of emotional disorders compromising mental health, it is essential to address the psychological factors of citizenship and in particular of students, for which they are imperative specific and early actions for the prevention and management of the psychological effects of a calamity of this magnitude, and the design of intervention programs to address perceived stress should be fundamental and a priority, formulate mental health policies, establish and activate protocols. In this way, this research enables the generation of university and health management initiatives to warn and alleviate the psychosocial consequences of the pandemic.

As mentioned (Liang et al 2020), government, administrative and higher education institutions are called upon to design and implement plans and programs to deal with stress, as was done by the University of Peking (China), through primers and manuals for the treatment of psychological problems of etiology associated with the COVID19 outbreak, manage institutional alliances with hospitals, psychological counseling centers and health sciences schools to set up specialized telephone and virtual lines to provide individual support.

\section{Bibliographic references}

Agustín E. Martínez, José Antonio Piqueras y Cándido J. (2015). Relaciones entre Inteligencia Emocional y Estrategias de Afrontamiento ante el Estrés. http://reme.uji.es/articulos/numero37/article6/article6.pdf

Brooks, S. K., Webster, R. K., Smith, L. E., Woodland, L., Wessely, S., Greenberg, N., \& Rubin, G. J. (2020). The psychological impact of quarantine and how to reduce it: rapid review of the evidence. In The Lancet (Vol. 
395, Issue 10227, pp. 912-920). Lancet Publishing Group. https://doi.org/10.1016/S0140-6736(20)304608

Caldera, M., Pulido, C., (2007). Niveles de estrés y rendimiento académico en estudiantes de la carrera de Psicología del Centro Universitario de Los Altos. Revista de Educación y Desarrollo, 7. Octubre-diciembre de 2007. http://www.cucs.udg.mx/revistas/edu_desarrollo/anteriores/7/007_Caldera.pdf

Calvo G., J. M., Sánchez P., R., \& Tejada, P. A. (2003). Prevalencia y factores asociados a ideación suicida en estudiantes universitarios. Revista De Salud Pública, 5(2), 123-143. Recuperado a partir de https://revistas.unal.edu.co/index.php/revsaludpublica/article/view/18406 doi: 10.15446/rsap

Gargurevich R., (2008). La autoregulación de la emoción y el rendimiento académico en el aula: El rol del docente Revista digital de investigaciòn en docencia Universitaria Año 4 No. 1 diciembre 2008. doi: 10.19083/ridu.4.10

Gross \& John (2003) Journal of Personality and Social Psychology. 2003, Vol. 85, No. 2, 348-362 Individual Differences in Two Emotion Regulation Processes: Implications for Affect, Relationships, and Well-Being James J. Gross Stanford University Oliver P. John University of California, Berkeley. http://espectroautista.info/ficheros/bibliograf\%C3\%ADa/gross2003idt.pdf and the levels of perceived stress using the adapted scale of perceived stress (EEP-14)

Gross J., John O., (2003). Individual Differences in Two Emotion Regulation Processes: Implications for Affect, Relationships, and Well-Being. Journal of Personality and Social Psychology., Vol. 85, No. 2, 348-362 http://espectroautista.info/ficheros/bibliograf\%C3\%ADa/gross2003idt.pdf

Lazarus, R.S., y Folkman, S. (1984). Estrés, valoración y afrontamiento. Editorial Springer Publishing Company.

Liang, L., Ren, H., Cao, R., Hu, Y., Qin, Z., Li, C., \& Mei, S. (2020). The Effect of COVID-19 on Youth Mental Health. Psychiatric Quarterly, 91(3). https://doi.org/10.1007/s11126-020-09744-3

Martínez, A., Piqueras J., y Cándido J. (2015). Relaciones entre Inteligencia Emocional y Estrategias de Afrontamiento ante el Estrés.

Mazo, R., Londoño, K., \& Gutiérrez, Y, F. (2013). Estrés académico en estudiantes universitarios. Informes Psicológicos, 13 (2), 121-134 http://reme.uji.es/articulos/numero37/article6/article6.pdf

Muñoz-Martínez, A., Vargas, R., \& Hoyos-González, J. (2016). Escala de Dificultades en Regulación Emocional (DERS): análisis factorial en una muestra colombiana / Difficulties in Emotion Regulation Scale (DERS): factor analysis in a colombian sample. Acta Colombiana de psicología, 19(1), 225-236. Recuperado de http://editorial.ucatolica.edu.co/ojsucatolica/revistas_ucatolica/index.php/acta-colombianapsicologia/article/view/984

Pineda D., Valiente R., Chorot P. Piqueras J. Sandín B. (2018). Revista de Psicopatología y Psicología Clínica, 23, 109-120, doi: 10.5944/rppc.vol.23.num.2.2018.21823 Invarianza factorial y temporal del Cuestionario de Regulación Emocional (ERQ)

UNFPA (2020). Covid-19: Un enfoque de género. Proteger la salud y los derechos sexuales y reporductivos y promover la igualdad de género. Recuperado de https://www.unfpa.org/es/resources/covid-19-unenfoque-de-g\%C3\%A9nero?page=1\%2C0\%2C3

Wang, M., Saudino, KJ Regulación de la emoción y estrés. J Adult Dev 18, 95103(2011). indicated that: "people vary in their ability to regulate emotions and cope with https://doi.org/10.1007/s10804-010-9114-7

Esta obra está bajo una Licencia Creative Commons

Attribución-NoCommercial 4.0 International 